\title{
Modeling of Debris Avalanche and Generated Water Waves: Application to Real and Potential Events in Montserrat
}

\author{
A. Mangeney ${ }^{1,2}$, PH. Heinrich ${ }^{1}$, R. Roche ${ }^{1}$, G. Boudon ${ }^{3}$ and J. L. Cheminée ${ }^{3}$ \\ 'Laboratoire de Détection et de Géophysique, Commissariat à l'Energie Atomique, B.P.12, 91680 Bruyères-le-Châtel, \\ France \\ ${ }^{2}$ Laboratoire d'Environnement et de Développement, Case 70-71, 2 Place Jussieu, F75251 Paris cedex 05, France \\ ${ }^{3}$ Observatoires Volcanologiques, IPGP, Case 89, 4 Place Jussieu, Tour 24, 75005 Paris, France
}

Received 21 July 1998; accepted 21 July 2000

\begin{abstract}
Tsunamis generated by a sudden entry of debris avalanches into the sea have caused some of the worst natural disasters in historic times. The evolution of the Soufriere Hill volcano's activity in Montserrat, Lesser Antilles, could lead to a dome collapse generating a tsunami. Two scenarios have been simulated here. In the first case, the potential entry into the sea of a debris mass of 40 millions of $\mathrm{m}^{3}$ at the mouth of the Tar River Valley, towards the East has been considered. In this case, the debris avalanche is approximated as a fluid entering the sea with a given front height and a given velocity. Sensitivity tests have shown that the simulated water wave is very sensitive to the imposed initial conditions. In order to have a more accurate source term in the tsunami model, we have developed here a numerical debris avalanche model. This model takes into account a Coulomb-type friction law and solves the vertically integrated long wave equations. A first application of this model has been made to simulate the $26^{\text {th }}$ December 1997 debris avalanche with an estimated volume of 60 millions of $\mathrm{m}^{3}$ that occurred in the White River valley, South of Montserrat. Preliminary results show that the debris avalanche path is very sensitive to the considered value of the friction angle $\delta$. An empirical value of $\delta$ lower than $15^{\circ}$, i. e. less than the value expected for debris avalanches, is required to reproduce the great mobility of this avalanche.
\end{abstract}

(C) 2000 Elsevier Science Ltd. All rights reserved.

\section{Introduction}

Numerical modeling can be very useful for evaluation of natural hazards related to volcanic activity. Stochastic approaches based on a probabilistic method have been also used for forecasting hazard (Sorensen, 1998). An

Correspondance to : A. Mangeney alternative approach is to develop numerical models treating the flow as a deterministic system, in which the rheological parameters are calibrated from past events. We follow here this last approach to assess natural hazards linked to debris avalanches and generated water waves in the volcanic island of Montserrat, Lesser Antilles.

Since 1995, the volcanic activity at Soufriere Hills in Montserrat has led to several pyroclastic flows (block and ash flows) reaching the sea and produced by the collapses of part of a growing lava dome in the English's Crater (Young et al., 1998). On the 26th December 1997, a debris avalanche resulting of a partial collapse of the southwestern rim of the crater and of a part of the lava dome with an estimated volume of about $60 \times 10^{6} \mathrm{~m}^{3}$ occurred in the White River valley, south of Montserrat (Figure 1).

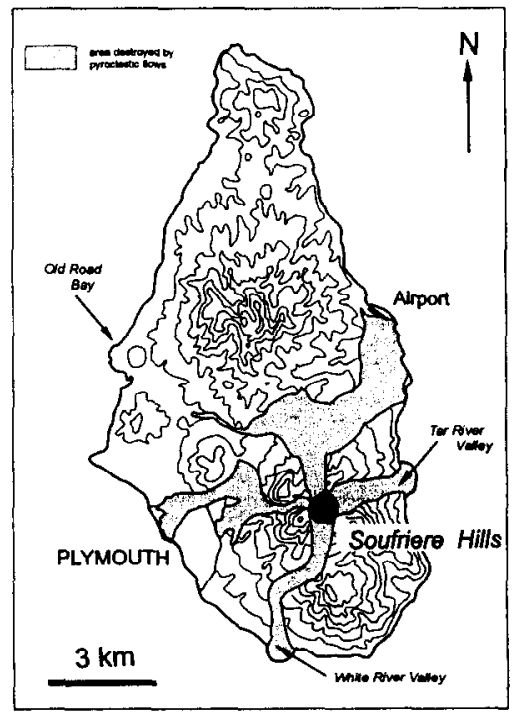

Fig. 1. Map of Montserrat

This debris avalanche was followed by a pyroclastic flow with approximately the same volume. Evidence of associated large water waves was observed ashore at Old 
Road Bay, situated at a distance along the coast of $10 \mathrm{~km}$ NNW from the landslide area (Calder et al., 1998). A similar scenario is likely to occur in the Tar River Valley, located in the horseshoe-shaped English's crater on the eastern flank of the volcano. This debris avalanche might lead to a tsunami propagating in the direction of Guadeloupe and Antigua islands, situated at about $50 \mathrm{~km}$ at the SE and NE of Montserrat, respectively.

Both debris avalanches and water waves generated by debris avalanches are still poorly understood (e. g., Sander and Hutter, 1992, 1996). As regards water waves, a 3D model solving the Euler's equations for a mixture of two fluids has been developed by Assier ct al. (1997). This model deals with the full interaction of debris avalanche and water, including the deformation of the entering mass (Heinrich et al., 1998). This model has been used here with given initial conditions for the geometry and the front of the debris mass entering the sea, in order to assess the hydraulic phenomena related to the potential debris avalanche in the Tar River valley, Montserrat. Sensitivity tests to initial conditions are investigated by varying the initial avalanche fronts and initial velocities of the mass entering the sea. The great sensitivity of the calculated water wave to these conditions shows the necessity to develop a debris avalanche model in order to have a more accurate source for the tsunami model. We present here a debris avalanche model solving the vertically integrated long wave equations in a coordinate system linked to the topography. This model requires few numerical resources and can be applied to real 3D topography. It takes into account a Coulomb-type friction law (Savage and Hutter, 1989) in a way similar to Naaim et al. (1997). A parametric study has been performed to evaluate the influence of the friction angle value on the avalanche path prediction.

\section{Numerical modeling of the generated water waves}

Fluid mechanics models are generally used to simulate subaerial or submarine landslides due to their observed fluid-like behaviors (Iverson, 1997; Jiang and Leblond, 1993; Sousa and Voight, 1995). To sinnulate the interaction of the debris avalanche with the sea, a 3D model based on Euler's equations has been developed, where water and debris avalanche are considered as a mixture of two fluids (Torrey et al., 1987; Assier et al., 1997). Thus, the problem consists in modeling the flow of only one fluid with variable density in time and space and the solid-water interface does not need to be dealt with. The numerical model solves the Euler's equations with a free-surface for a mixture of two incompressible fluids using an Eulerian finite-difference method. Details of the numerical method are given in Heinrich (1992) and Assier et al. (1997). In this study, the debris avalanche is assumed to be a non-viscous fluid flowing down a frictionless slope and is considered to be non-porous while sliding into water. Since no diffusion is calculated between water and sediments in the numerical applications presented in this paper, the mixture is made of two separate media. The $2 \mathrm{D}$ version of this numerical model has been validated by laboratory experiments consisting in the submarine slide of a gravel mass along an inclined plane (Assier et al., 1997). The nonlinear governing equations of the mixture can be then written as follows :

$$
\begin{aligned}
& \frac{\partial \rho}{\partial t}+\nabla \cdot(\rho \mathbf{v})=0 \quad \text { (continuity equation) } \\
& \frac{\partial \mathbf{v}}{\partial t}+\mathbf{v} \cdot \nabla \mathbf{v}=\mathbf{g}-\frac{\nabla p}{\rho} \quad \text { (momentum equation) } \\
& \frac{\partial \mathbf{F}}{\partial t}+\nabla \cdot \mathbf{F v}=0 \quad \text { (transport equation) } \\
& \nabla \cdot \mathbf{v}=\frac{\rho_{2}-\rho_{1}}{\rho_{1} \rho_{2}} \nabla \cdot \mathbf{j} \quad \text { (diffusion equation) }
\end{aligned}
$$

where $\mathbf{v}$ is the 3D fluid velocity vector of the mixture; $\mathbf{g}$ is the gravity acceleration; $p$ is the pressure; $\mathbf{j}$ is the diffusion flux and is set at 0 , since no dilution of debris material into water is calculated; $F$ is the fractional volume of the cell occupied by the mixture and is used to calculate the freesurface evolution. The mixture is composed here of sea water taken as a fluid of density $\rho_{1}=1$ and of the debris material treated as an homogeneous fluid of density $\rho_{2}=2$. The mixture density $\rho$ is defined by the relation $(\rho=(1-c) \rho$ ${ }_{1}+c \rho_{2}$ ), where $c$ is the volume fraction of sediments. A unit value of $c$ corresponds to a highly concentrated part of sediments and a 0 value of $c$ indicates the water region.

Numerical simulations of the water waves generated by a parallelepiped of sediments with a volume of $40 \times 10^{6} \mathrm{~m}^{3}$ in a U-shaped chute with a $800 \mathrm{~m}$ width and a slope of $10 \%$ have been performed for various values of the avalanche front height and initial velocity. These values are in the range of those calculated and observed debris avalanches of volcanic origin (e. g., Sousa and Voight, 1995) and are similar to those estimated for the 26 December 1997 landslide in Montserrat. The topography and bathymetry are assumed to be symmetric with respect to the axis of the Tar River valley (i. e. $x$-axis), modeled as a U-shaped, west-east orientated depression of $800 \mathrm{~m}$ wide. Both topography and bathymetry are uniform in the $y$-direction (i. e. south-north direction), excepted for the U-shaped valley. The 3D computational domain extends over $8 \mathrm{~km}$ from wcst to cast in the $x$ direction, over $4.5 \mathrm{~km}$ from south to north in the $y$-direction and from $-750 \mathrm{~m}$ to $400 \mathrm{~m}$ in the vertical direction (Figure 2).

The relative importance of the initial avalanche fronts and of the initial velocities is investigated by varying these parameters in 20 case studies ( 5 velocities and 4 front heights). Initial velocities range from 10 to $70 \mathrm{~ms}^{-1}$ and initial front heights from 15 to $45 \mathrm{~m}$. Figure 3 compares the maximum calculated watcr height by varying these parameters and at a distance of $3 \mathrm{~km}$ from the impact location $(x=3 \mathrm{~km})$. 


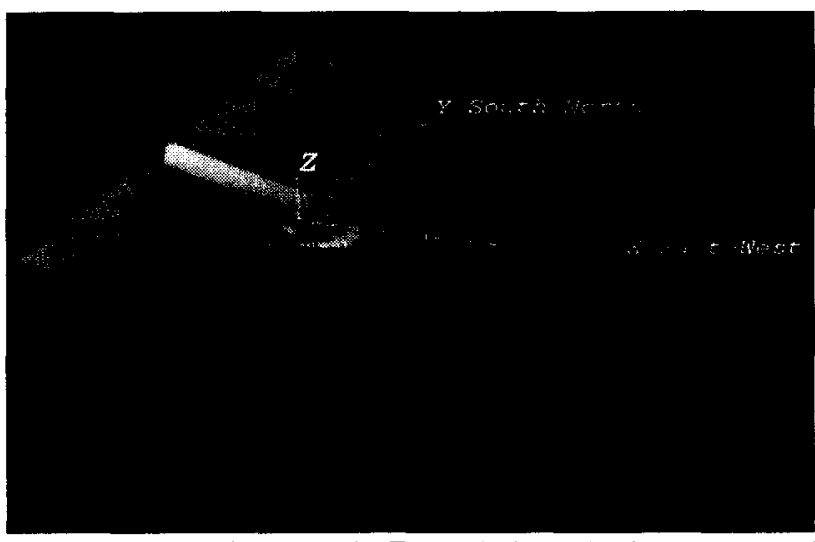

Fig. 2. 3D computational domain. The vertical scale has been exaggerated by a factor of 3 . The interval between ticks is $1000 \mathrm{~m}$ on the horizontal axis $(x, y)$ and $100 \mathrm{~m}$ on the vertical axis. The debris avalanche flows down a $800 \mathrm{~m}$ wide, $\mathrm{U}$-shaped valley before impacting water.

Results show that the computed height is strongly dependent on the avalanche front and initial velocity within the range of the studied values. In particular, for a given front height, the calculated maximum elevation seems to vary approximately linearly with the initial velocity for velocity heigher than 10 $\mathrm{ms}^{-1}$. Figure 3 indicates that the dominant parameter controlling wave heights is the height of the avalanche front. Note that a lactor of 6 difference in avalanche velocity has only the same effect as a factor of 2 variation in front height. These results show the necessity to understand and to model the rheological behavior of debris avalanches in order to have an accurate source in the tsunami model.

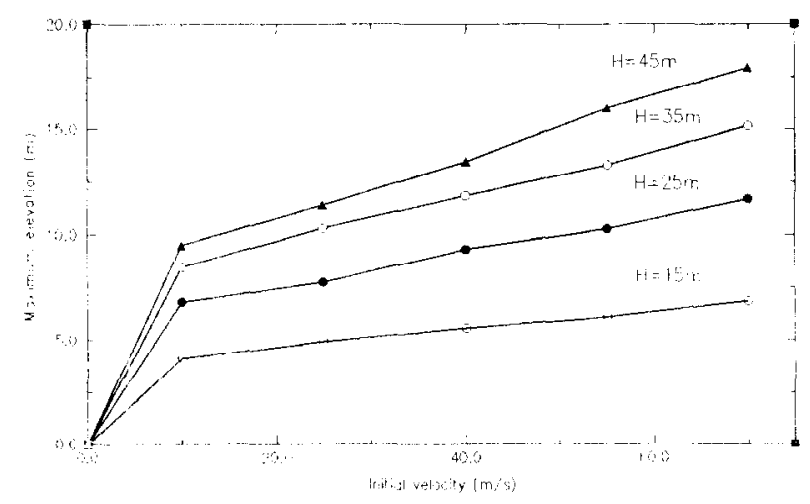

Fig. 3. Conparisons between maximum calculated tsunami heights at a distance of $3 \mathrm{~km}$ from the impact location. The maximum heights of the 20 numerical experiments (represented by circles) are expressed as a function of the initial slide velocity. The 4 solid lines represent the 4 studied geometries

\section{The debris avalanche model}

A numerical debris avalanche model has been developed requiring few numerical resources. in order to be easily applied to real 3D topography. This model solves the vertically integrated long wave equations in a coordinate system linked to the topography. Following Naaim et al. (1997), a Coulomb-type friction law has been introduced. Mass and momentum equations can be written as

$$
\begin{aligned}
& \frac{\partial u}{\partial t}+u \frac{\partial u}{\partial x}+v \frac{\partial u}{\partial y}=-g \cos \theta \frac{\partial h}{\partial x}-g \sin \theta_{x}+F_{x} \\
& \frac{\partial v}{\partial t}+u \frac{\partial v}{\partial x}+v \frac{\partial v}{\partial y}=-g \cos \theta \frac{\partial h}{\partial y}-g \sin \theta_{y}+F_{y}
\end{aligned}
$$

where $\theta$ is the steepest slope angle, $\theta_{x}$ and $\theta_{y}$ the slope angles along $x$ - and $y$-axis respectively, and $\mathbf{v}=(u, v)$ is the depth-averaged horizontal velocity, $h$ the fluid height, $g$ is the acceleration due to gravity, and $F$ the well-known Coulomb-type friction law

$$
F_{\mathrm{i}}=-g \cos \theta \operatorname{tg} \delta \frac{u_{\mathrm{i}}}{\|\mathbf{u}\|}
$$

where $i=x, y$ and $\delta$ is the dynamic friction angle $\left(20^{\circ}<\delta<40^{\circ}\right.$ for debris avalanche). The numerical model is based on a shock-capturing method, similar to those currently used to simulate compressible inviscid flows with shock waves. This method appears to be remarkably stable and accurate when dealing with significant discontinuities. The precision and stability of this model have been studied comparing the results with those of an analytical solution for dam-break type problems (Mangeney et al., 1998). The present model can be useful in practice for fluid flows where non-linear effects are important or where strong changes (hydraulic jump) can be expected. Equations (5-7) provide a simplified representation of debris and dense snow avalanches dynamics, in particular it does not contain any constitutive relation for the fluid. Nevertheless, this model gives a first approximation of the velocity and runout distance of debris avalanches (Naaim et al., 1997) and has the advantage to use only one parameter. Note that the more complex equations developed by Savage and Hutter (1989) for a Coulomb-frictional material may be easily introduced in our model.

\section{Simulation of the Boxing Day debris avalanche}

A first application of our model to the debris avalanche that occurred on the 26th December 1997 in the White River valley in Monserrat has been carried out. We use here the topography of Montserrat and an estimation of the initial released volume of the debris avalanche given by the Monserrat Volcano Observatory (Calder et al., 1998). A debris mass with an initial parabolic shape and a volume of 

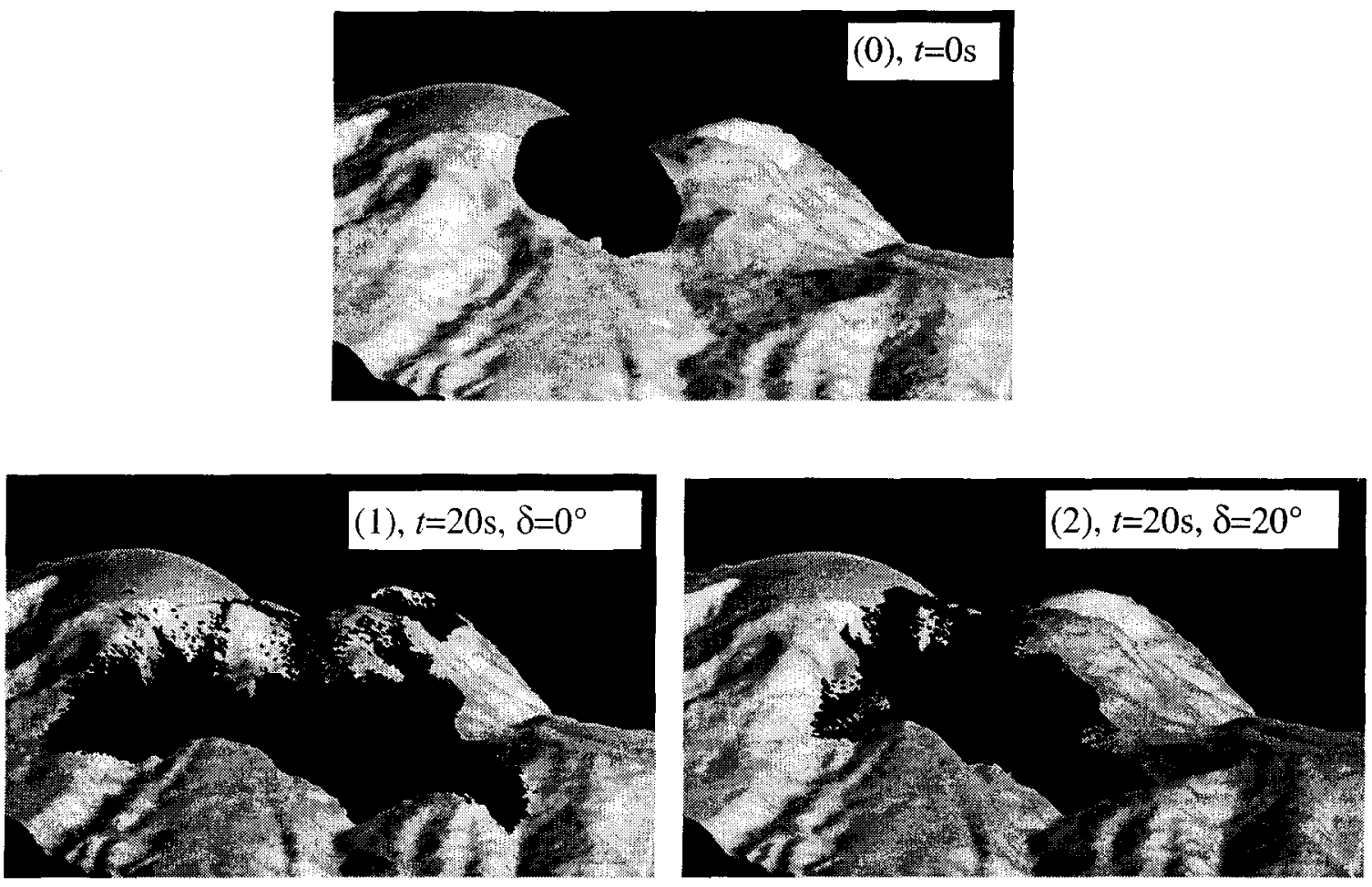

Fig. 4. Modeling of the 26th December debris avalanche in the White River valley, Montserrat. A volume of 60 millions of $\mathrm{m}^{3}$ is released from rest at the initial instant. The results of two simulations at time $t=20$ seconds are shown here: (1) without friction and (2) with a friction angle $\delta=20^{\circ}$. The topography of Montserrat used here has been provided by the Montserrat Volcano Observatory.

$60 \times 10^{6} \mathrm{~m}^{3}$ is released from rest at the initial instant (Figure 4a). A series of numerical tests have been performed for different values of the friction angle. From these preliminary results, it appears that the predicted avalanche path depends strongly on the value of the friction angle (Figure $4 b, c)$. This result is in agreement with those obtained by Hutter (1996) on simplified geometry. Two extreme cases are presented here, the first one is obtained without taking any friction into account and the second one using a friction angle $\delta=20^{\circ}$. In the first case, the debris avalanche overflows the topographic relief and flows into the surrounding valleys while in the second case, the avalanche is confined at any time in the White River valley.

It has to be noted that for friction angles in the range of those estimated for debris avalanche $\left(\delta>20^{\circ}\right)$, the avalanche stops more than $1 \mathrm{~km}$ from the shoreline. In fact the debris avalanche has been estimated to stop approximately $300 \mathrm{~m}$ from the shoreline. Obviously, this simple Coulomb-type friction model cannot reproduce the great mobility of debris avalanches in Montserrat. In particular, the value of $\delta$ is most likely to be time and space dependent. However, it can be seen as an empirical model considering $\delta$ as an empirical parameter. In fact, when a value of $15^{\circ}$ for $\delta$ is assumed, the avalanche stops just before reaching the sea with a velocity in the range of those observed. The low value of $\delta$ is a consequence of the widely observed ability of large avalanches to travel distances much larger than expected from classical models of slope failure. Several attempts have been made to explain this phenomena and in particular the volume-dependence of this ability (see e. g. Kilburn and Sorensen, 1998 ; Dade et al., 1997). The great mobility of the $26^{\text {th }}$ December debris avalanche can be partly explained by the presence of an important part of the active lava dome. The fragmentation during the flow of the lava dome, not totally degassed, produce gases which accelerate the debris avalanche.

\section{Conclusion}

Numerical tests have shown that the results of the tsunami model are sensitive to initial conditions on the velocity and the front height of the mass entering the sea. On the other hand, it appears that the prediction of debris avalanche model depends significantly on the value of the friction angle. The empirical value of the friction angle required to reproduce the great mobility of the Boxing Day avalanche in Montserrat is lower $\left(\delta \leq 15^{\circ}\right)$ than the value expected for debris avalanches. This is in agreement with the widely observed and not yet explained great mobility of large debris avalanches. The next development is to compare of numerical results with data on debris deposits in order to determine empirically friction angles for debris avalanches of volcanic origin. 
Acknowledgments. The authors are grateful to Dr. Yves Caristan, President of the Comité Supérieur d'Evaluations des Risques Volcaniques in France and Dr. J. Bouchez, head of the Laboratory of Detection and Geophysics, CEA. France for their support. The authors would like also to thank the Montserrat Volcano Observatory and the Guadeloupe Volcano Observatory for providing topographic data.

\section{References}

Assier, S., C. Mariotti, and Heinich, Ph., Numerical simulation of submarine landslides and their hydraulic effects, J. Wirwy., Port, Coast., and $O_{C}$. Engrg., ASCE, 123, 149-157, 1997.

Calder, E., Young, S., Steve, R., Sparks, S., and MVO staff, Montserrat Volrano Obsenatory. Special Report 06, The Boxing day collapse, 1998.

Dade, W. B., Hogg, A. J., and Huppert, H. E., Long-runout rockfalls, J. Geophys. Res., 1997.

Heinrich, Ph., Nonlinear water waves generated by submarine and aerial landslides, J. Wirwy., Port, Coast, and OC. Engrg., ASCE, I18(3), 249266,1992

Heinrich, Ph., Mangeney, A., Guiboury, S., Roche, R., Boudon, G. and Cheminée, J. L., Simulation of water waves generated by a potential debris avalanche in Montserrat, Lesser Antilles, Geophys. Res. Lett., 25(119). 3697-3700, 1998.

Iverson, R. M. . The physics of debris flows, Rev. Geophys., 35, 245-296, 1997.

Jiang, L. and Leblond, P.H., Numerical modeling of an underwater
Bingham plastic mudslide and the waves which it generates, $J$. Geophys. Res., 98, 304-317, 1993.

Kilburn, C. R. J. and Sorensen, S. A., Runout lenghts of sturzstroms : The control of initial conditions and of fragment dynamics, J. Geophys. Res., $10.3(B 8), 17,877-17,884,1998$.

Mangeney, A., Heinrich, Ph., and Roche, R., Analytical and numerical solution of dam-break problem for application to water floods, debris and dense snow avalanches, Pure Appl. Geophys., in press, 1998.

Naaim, M., Vial, S., and Couture, R., Saint-Venant approach for rock avalanches modelling, Saint-Venant Symposium, August 28 29, Paris, 1997.

Sander, J. and Hutter, K., Evolution of weakly non-linear channelized shallow water waves generated by a moving boundary, Acta Mech., 91, 119-155, 1992.

Sander, J. and Hutter, K., Experimental and computational study of channelized water waves generated by a porous body, Acta Mech., 115 , 133-149, 1996.

Savage, S. B. and Hutter, K., The motion of a finite mass of granular material down a rough incline, $J$. Fluid Mech., 199, 177-215, 1989.

Sorensen, S. A., Risk evaluation with stochastic models of lava flows, Ann. Geophysicae, C 1212, 1998.

Sousa, J. and Voight, B., Multiple pulsed debris avalanche emplacement at Mount St. Helens in 1980 : Evidence from numerical continuum flow simulations, J. Volcanology and Geothermal Res., 66, 227-250, 1995.

Torrey, M.D., Mjolsness, R.C., and Stein, L.R., Nasa-Vof3D : a threedimensional computer program for incompressible flows with free surfaces, Report LA11009-MS, Los Alamos National Laboratory, 1987.

Young, S., Robertson, Lynch, Miller, Ambeh, Aspinall, Shepherd, Sparks and MVO staff, Overview of the volcano and the eruption with a chronology, Geophys. Res. Lett., 25(18), 3389-3392, 1998. 